\title{
Measurement of rf Voltages on the Plasma-Touching Surfaces of ICRF Antennas*
}

\author{
D. J. Hoffman, F. W. Baity, G. L. Bell, T. S. Bigelow, J. B. O. Caughman, \\ R. H. Goulding, G. R. Haste, P. M. Ryan, H. Zhang
}

Oak Ridge National Laboratory, P. O. Box 2009, Oak Ridge, TN 37831

\begin{abstract}
Measurements of the rf voltages on Faraday shields and protection bumpers have been made for several loop antennas, including the mock-up antenna and Al for JET, the original antenna for Tore Supra, the present ASDEX-U antenna, and the folded waveguide. The loop antennas show voltages that scale to $\approx 12 \mathrm{kV}$ for a maximum input voltage of $30 \mathrm{kV}$ with $0 / 0$ phasing. The voltages are dramatically reduced for $0 / \pi$ phasing. These voltages are significant in that they can substantially increase the rf sheath potential beyond the levels associated with the simple electromagnetic field linkage from the current straps that results in plasma heating. In this paper, we investigate and measure the source of these voltages, their scaling with antenna impedance, and the differences between the loop arrays.
\end{abstract}

\section{INTRODUCTION}

$\mathrm{RF}$ antenna voltages have been characterized by unbalanced transmission line elements or lumped circuit elements where the back plane and side walls of the radiating structure are modeled as a hard ground. Through proper modeling of the plasma, linked to magnetostatic antenna models that yield the characteristic impedances in the structure, line voltages and currents can be predicted.

While these types of simulations can be used to evaluate the electromagnetic interaction between the edge plasma and the antenna structure, the models need to be refined to account for the finite width of the return current channel in the ground plane. These current channels provide a net inductance, generating nonzero $\mathrm{rf}$ voltages in the so-called ground plane. This net voltage can result in both poloidal electric fields (dominated by the electromagnetic portion of the wave) and radial/toroidal electric fields which interact with the edge plasma.

The peak voltage in ICRF antenna structures is typically $30-40 \mathrm{kV}$ and is found on the radiating structure and/or the feed line structure. The typical poloidal electromagnetic electric field at the antenna/plasma interface is on the order of 40 $60 \mathrm{kV}$ (peak) over $60-80 \mathrm{~cm}$, or about $0.5-1 \mathrm{kV} / \mathrm{cm}$ peak. Thus, for these ground voltages to be significant, they must either have a magnitude that is on the order of $0.1 \times$ the maximum voltage or generate electric fields at the plasma surfaces that are on the same order as the electromagnetic component. It should be noted that if an rf voltage of 1000 Volts is applied to a Faraday shield rod of $1.3 \mathrm{~cm}$ radius, the electric field dissipated through a plasma ground plane can be as high $1.6 \mathrm{kV} / \mathrm{cm}$. This determines the magnitude where these voltages may be significant. Thus, voltages on the order of a few $\mathrm{kV}$ on the plasma facing

*Research managed by the Office of Fusion Energy, U. S. Department of Energy, under contract DE-AC05-84OR21400 with Martin Marietta Energy Systems, Inc.

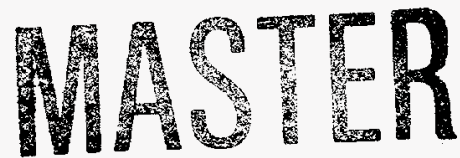

RF conf. paper-2a 


\section{DISCLAIMER}

This report was prepared as an account of work sponsored by an agency of the United States Government. Neither the United States Government nor any agency thereof, nor any of their employees, makes any warranty, express or implied, or assumes any legal liability or responsibility for the accuracy, completeness, or usefulness of any information, apparatus, product, or process disclosed, or represents that its use would not infringe privately owned rights. Reference herein to any specific commercial product, proces̃s, or service by trade name, trademark, manufacturer, or otherwise does not necessarily constitute or imply its endorsement, recommendation, or favoring by the United States Government or any agency thereof. The views and opinions of authors expressed herein do not necessarily state or reflect those of the United States Government or any agency thereof. 


\section{DISCLAIMER}

Portions of this document may be illegible in electronic image products. Images are produced from the best available original document. 
components of the antenna structure may impact antenna performance via edge interactions. Significant voltages on the Faraday screens may be related to the formation of hot spots observed on the Tore Supra, JET and ASDEX-U antennas, especially in non $0 / \pi$ phasings.

\section{MEASUREMENTS OF GROUND PLANE VOLTAGES}

It is normally difficult to make rf voltage measurements by conventional probes because the measuring cable impedance of $50 \Omega$ can be sufficiently low to affect or reduce the voltage being measured. Therefore, two different techniques were utilized to measure these antenna structure voltages. High impedance probes were used first. Their signals were the fed into a Hewlett-Packard (HP) 8753C Network Analyzer to measure magnitude and phase relative to a reference voltage. The high impedance probes were either the active $1 \mathrm{M} \Omega$ probe by HP or 13:1 rf transformers from Mini-Circuits. A third type of probe was a simple plate welded onto the end of an inner conductor. This, was in turn, sheathed by a Teflon casing. When touched to an rf surface, a high impedance capacitive divider was achieved. The latter configuration achieved the least stray pick-up, although it was difficult to eliminate all pick-up. In order to minimize the pick-up, the path of the connecting cable to the network analyzer was held as fixed as possible, and care was taken to keep the probe body as close to perpendicular to the rf surfaces as possible. Furthermore, the reference voltage was taken from the current strap itself. The reference site was chosen to be either on the strap at the voltage maximum (provided the probe did not "load" the antenna when touching it at the voltage maximum) or in a matched feed line (which never loaded the antenna).

Most of the rf voltage measurements on the various antennas were patterned after measurements on the original Tore Supra Faraday shield, where voltages were normalized to the input section of the line. However, this was not the case for all measurements.

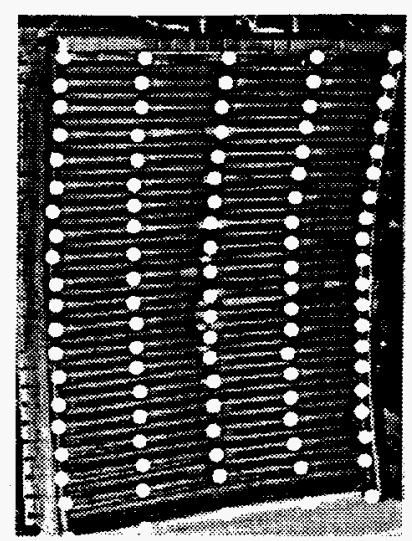

FIGURE 1 Picture of the Original Tore Supra antenna Faraday shield plus frame assembly. The white dots are at the sites of the if voltage measurements.
The discussion that follows here is specific to the measurements made on the Tore Supra antenna. Three phasings were measured: singly energized, $0 / 0$ phasing and $0 / \pi$ phasing. In each of these cases, the rf voltages measured were normalized to a maximum of $40 \mathrm{kV}$ peak, which occurs on the capacitors in the Tore Supra system. This value was chosen because that voltage is usually sufficient to convey $2 \mathrm{MW}$ per strap, depending on plasma conditions. Figure 1 shows the positions on the Tore Supra Faraday Shield where probe measurements were taken. Figures 2 and 3 show the corresponding surface plots of the voltages for monopole and dipole phasings.

The characteristics of the plots are as follows. First, there seems to be a virtual ground at the poloidal mid plane of the antenna. The upper half is $180^{\circ}$ out of phase with the lower half. The frame voltages are also out of phase with the current strap feed voltages. It 


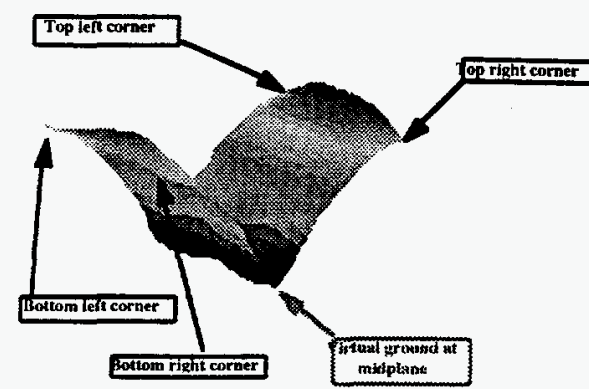

FIGURE 2 Surface plot of the if voltages on the original Tore Supra antenna frame in monopole phasing.

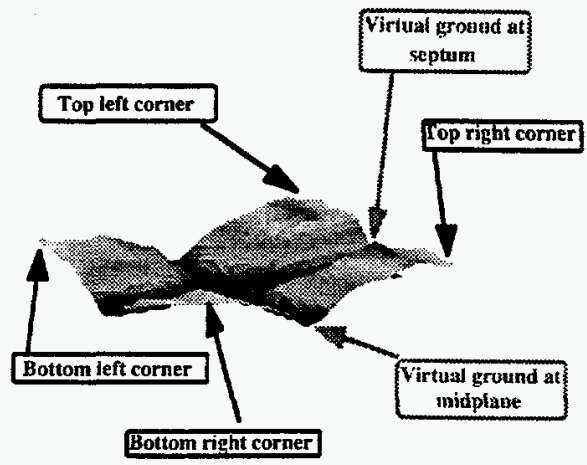

FIGURE 3 Surface plot of the if voltages on the original Tore Supra antenna frame in dipole phasing.

seems that the septum typically has $15 \%$ higher voltages than the corners of the antenna. For monopole, the voltages were typically $3.3 \mathrm{kV}$ per $40 \mathrm{kV}$. In dipole, the frame voltages were only $830 \mathrm{~V}$ per $40 \mathrm{kV}$. In dipole, there is an additional virtual ground plane toroidally midway between the straps. In order to assess the frame voltage per $2 \mathrm{MW}$ per strap, loading differences must be included. Monopole loading is typically 1.5-2 times dipole, so monopole frame voltages should be $\approx 2.5$ times higher than dipole.

Another significant characteristic is that the voltages of the single strap look like a non-symmetric monopole. The septum and side wall of the energized strap had voltages on the order of $2 \mathrm{kV}$, while the far wall on the unenergized, detuned strap measured 1.3 $\mathrm{kV}$ per $40 \mathrm{kV}$. The monopole or dipole can be simulated by adding two single strap voltages. In fact, the vector addition of a single strap's voltages plus a second (mirror imaged) strap's voltages on the frame yielded the measured monopole or dipole voltages within $10-15 \%$.

Other antennas displayed the same behavior. This included the JET A1, the mock-up of the JET A2, ASDEX-U, and a single energized test antenna at ORNL. In all cases, there was a virtual ground in the poloidal mid plane. In all dipole cases, there was a toroidal virtual ground as well. For reasons not yet known, the A2 mock-up, A1, and ASDEX-U antennas showed approximately 12,9 , and $6 \mathrm{kV}$ on the frames per $30 \mathrm{kV}$ peak in the system in monopole. Dipole voltages were $3,<1$, and $2 \mathrm{kV}$ respectively.

\section{MODELING}

It was suspected that antenna wall inductances were the source of the frame voltages. Although the frame itself offers many low inductance paths to ground, the strap's currents induce such a narrow current channel that these alternate paths could not be used. Thus we chose a very simple (Figure 4), distributed circuit model of the strap plus two side walls and a septum. The strap inductances $(2.3 \mathrm{nH} / \mathrm{cm})$, three parallel side wall inductances $(0.5 \mathrm{nH} / \mathrm{cm}$ each--equivalent to $0.17 \mathrm{nH} / \mathrm{cm}$ for the aggregate), and capacitances $(0.8 \mathrm{pF} / \mathrm{cm})$ were calculated from magnetostatic models of the Tore Supra antenna. Since all frames exhibited a ground plane in the mid plane of the antenna, the zeroeth nodes' voltages were set to be at zero: The circuit was driven with strap currents in the zeroeth nodes. 
Magnetostatic models were used to determine the return currents in the near sidewall (40\%), septum (40\%), and the far side wall (20\%).

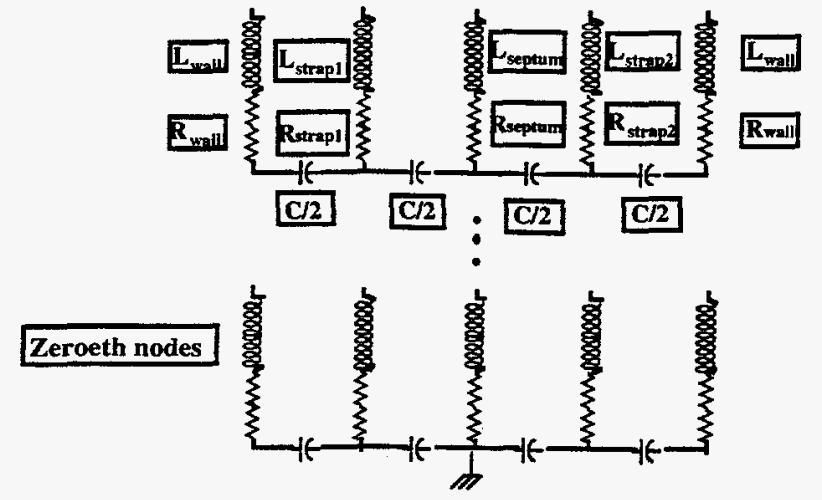

FIGURE 4 Simple circuit of sidewall, strap inductances that result in non-zero sidewall voltages.
Despite many simplifications, the model yielded results in good agreement with the Tore Supra antenna measurements. In the singly energized strap case, the septum and near side walls measurements were within $6 \%$ of the calculation. The far wall measurement was $1.3 \mathrm{kV}$, while the calculation was only $0.9 \mathrm{kV}$. In monopole, the calculation was $15 \%$ lower than the sidewall measurement and matched the septum measurement. In dipole, the model predicted $1 \mathrm{kV}$ at the sidewall vs $0.83 \mathrm{kV}$ measured

Although crude, the circuit model appears to have captured the essence of the voltage source and agrees with the measurements. Since the model has the character of the if frame voltages, other phasings can be evaluated. In particular, $\pi / 2$ phasing shows the frame voltages to be $2.3 \mathrm{kV}$.

Four identical straps, energized in the same manner as the two strap arrays yield interesting results. First, $1000 \mathrm{~A}$ in four straps phased either by $0 / \pi / 0 / \pi$ or $0 / \pi / \pi / 0$ yields the lowest voltages, approximately $1.2 \mathrm{kV}$. The location of the large voltage is at the edge in the former, while in the middle in the latter. The $0 / 0 / \pi / \pi$ case results in $3.6 \mathrm{kV}$ at the edge. In monopole, energizing one, two, three, and four straps respectively yielded $2.9,5.4,6.7$, and $8.0 \mathrm{kV}$ maximum. Due to the symmetry, $0 /(\pi / 2) / \pi,(3 \pi / 2)$ yields only $2.5 \mathrm{kV}$ on the frame. Roughly speaking, an n-strap array phased by $2 \pi / n$ is almost equivalent to $0 / \pi / \ldots$ phasing.

\section{CONCLUSIONS}

The voltages measured on the frames of antennas can be very high in phasings that seem to yield the worst results on tokamaks (such as frame overheating or inefficient plasma heating); they are lowest for the best phasings (generally $0 / \pi$ ). While the measurements and models are in an evolutionary stage, they still show relatively good agreement. How the voltages scale with antenna geometry or how much the plasma ameliorates them is not known, but the magnitude is sufficiently high to be important. It is noted that the four strap array models show that FWCD arrays designed from identical modules do have voltages like the best heating phasings. Coping with the voltages can be achieved in three ways: 1) operating at phasings where net current in the straps sums to zero; 2) designing hardware to minimize the plasma flux impinging on high voltage antenna surfaces and; 3) constructing low impedance antenna structures. To date, the first two methods are already employed in many ICRF experiments. 